\title{
Governança, intersetorialidade e participação social na política pública: o Conselho Nacional dos Direitos da Pessoa Idosa
}

\author{
Governance, intersectoriality and social participation in public \\ policy: the National Council on the Rights of the Elderly
}

Michele Souza e Souza ${ }^{1}$

Cristiani Vieira Machado ${ }^{1}$

${ }^{1}$ Escola Nacional de Saúde Pública Sergio Arouca, Fiocruz. R. Leopoldo Bulhões 1480, Manguinhos. 21041-210 Rio de Janeiro RJ Brasil.

michele.ifcs@gmail.com

\begin{abstract}
Aging is a complex phenomenon that requires different types of public policies. In 2002, the National Council for the Rights of the Elderly (CNDI) was created as a governance structure to enhance the guarantee of rights through coordination between sectors of government and civil society. The article seeks to analyze the CNDI based on the description of the institutional configuration and characterization of its operation in the proposal of strategies for implementing and monitoring the main policies for the elderly. The analytical framework of public policy analysis was used, with emphasis on the concept of governance, laws and documents, highlighting the minutes of Council meetings, as well as semi-structured interviews. As a result, it was possible to detect the importance of these spaces that enable the influence and control of institutionalized civil society over the State. However, difficulties of referral of the actions, obstacles in the relationship between the social actors were observed, as well as insufficient involvement of some government agencies. In the context of accelerated demographic chang$e s$, social inequalities and vulnerability of the elderly population, this governance strategy per se has not been sufficient to ensure the realization of the rights envisaged.
\end{abstract}

Key words Governance, Elderly, Public policies, Social rights, Intersectoriality
Resumo $O$ envelhecimento é um fenômeno complexo que requer diferentes tipos de políticas públicas. Em 2002 foi criado o Conselho Nacional dos Direitos da Pessoa Idosa (CNDI) como estrutura de governança para fortalecer a garantia de direitos através da articulação entre setores de governo e sociedade civil. O artigo objetiva analisar o CNDI a partir da descrição da configuração institucional e caracterização da sua atuação na proposição de estratégias de implementação e acompanhamento das principais politicas para os idosos. Utilizou-se o referencial de análise de políticas públicas, com ênfase no conceito de governança. Analisaram-se leis e documentos, com destaque para as atas das reuniões do Conselho, além de entrevistas semiestruturadas. Como resultado foi possivel atestar a importância desses espaços que possibilitam a influência e controle da sociedade civil institucionalizada sobre o Estado. Porém, observaram-se dificuldades de encaminhamento das ações, entraves na relação entre os atores sociais e insuficiente envolvimento de alguns órgãos governamentais. Diante das aceleradas mudanças demográficas, de desigualdades sociais e vulnerabilidade de parte da população idosa, essa estratégia de governança per se não tem sido suficiente para assegurar a efetivação dos direitos previstos.

Palavras-chave Governança, Idosos, Políticas públicas, Direitos sociais, Intersetorialidade 


\section{Introdução}

O Brasil tem experimentado uma alteração da estrutura etária caracterizada por aumento da participação de idosos na população total. Entre 1991 e 2012, a proporção de idosos na população subiu de 9,7 para $13,7 \%{ }^{1}$.

Em consequência, modificou-se o perfil de mortalidade da população, com aumento da incidência de doenças crônico-degenerativas como as cardiovasculares e neoplasias ${ }^{2}$, que podem exigir cuidados prolongados por anos $\mathrm{s}^{3,4}$.

O segmento de idosos é heterogêneo. Parte destes apresenta autonomia e capacidade de gerir sua vida nas dimensões econômica, social e cognitiva, desempenhando papéis essenciais em suas famílias e meio social. Por outro lado, parte sofre com o aparecimento e/ou agravamento de doenças incapacitantes ou com a escassez de rendimentos.

Assegurar um contexto propício e favorável ao envelhecimento requer políticas amplas que levem em consideração o idoso, a comunidade, a família e seu contexto social. Tais políticas devem envolver o Estado e a sociedade civil, de forma a favorecer o acesso dos idosos aos serviços e recursos, permitindo que se realizem como cidadãos independentes e sejam tratados com dignidade ${ }^{5}$.

Considerando-se o envelhecimento como um fenômeno complexo e multifacetado que exige diferentes tipos de políticas públicas, a intersetorialidade, ou seja, a construção conjunta de ações e políticas entre diferentes setores, tais como saúde, assistência social e direitos humanos, se configura como um dos maiores desafios para a proteção social e promoção da qualidade de vida dos idosos ${ }^{4}$. Além disso, a implementação de políticas para esse grupo requer a participação de diferentes atores sociais, incluindo os movimentos de representação dos idosos.

No Brasil, em 2002, foi criado o do Conselho Nacional dos Direitos da Pessoa Idosa (CNDI) como estrutura de governança para fortalecer as políticas públicas para a população idosa por meio da articulação intersetorial e da participação social dos atores relevantes para a proteção social aos idosos.

$\mathrm{O}$ artigo tem como objetivo analisar a atuação do CNDI de 2002 a 2016, como um espaço inovador de governança em uma política públi$\mathrm{ca}$, que busca articular setores de governo e sociedade civil na garantia dos direitos desse grupo populacional ${ }^{6}$. O estudo buscou descrever a configuração institucional do CNDI e caracterizar a sua atuação na proposição de estratégias de im- plementação e no acompanhamento da Política Nacional do Idoso (PNI) e do Estatuto do Idoso no país.

\section{Metodologia}

Utilizou-se o referencial de análise de políticas públicas, com destaque para o conceito de governança da política, na perspectiva da atuação e das relações entre Estado e sociedade civil ${ }^{7}$. Compreende-se governança como o conjunto de estratégias utilizadas para governar, considerando os mecanismos (redes, diálogos) e padrões de articulação entre os atores sociais, que podem ser estatais e não estatais. Assume-se que a formulação e gestão de políticas públicas não deve se limitar ao Estado, mas envolver a participação de atores sociais interessados e implicados com determinada política. Essa perspectiva destaca uma abordagem relacional em que redes sociais/comunidade se configuram como parte integrante das estruturas de construção de políticas públicas ${ }^{8-10}$.

O processo de negociação e diálogo entre diversos atores envolvidos é fundamental para coordenar as políticas além do escopo setorial. A intersetorialidade pode ser entendida como o "enfrentamento do desafio da integração e articulação de atores, processos e estruturas que foram construídos e operam, tradicionalmente, de forma fragmentada" ${ }^{\prime 1}$. Nesse sentido, o CNDI é uma instância que visa favorecer a articulação e compartilhamento de atribuições entre diferentes setores, visando à implementação, densidade e abrangência das políticas para os idosos.

Foram priorizados dois eixos de análise: (i) Configuração político-institucional, que compreendeu a estrutura, a organização e a participação dos atores estatais e não-estatais no Conselho; e (ii) Agenda politica, que diz respeito aos temas priorizados nas reuniões do CNDI.

As estratégias metodológicas envolveram análise de leis e documentos referentes ao CNDI, com destaque para as atas das reuniões do Conselho realizadas entre novembro de 2002 e abril de 2016, solicitadas através do Sistema Eletrônico do Serviço de Informações ao Cidadão (eSIC). No período foram realizadas 81 reuniões, das quais foram analisadas as 54 atas disponíveis (66\% do total de reuniões), distribuídas entre todas as gestões bienais do período. Destas, 42 tinham a relação completa de participantes (77,7\% das atas analisadas).

Em caráter complementar, foram realizadas quatro entrevistas semiestruturadas com in- 
formantes-chave que atuaram no CNDI por ao menos dois anos, em diferentes gestões: um exSecretário Executivo do CNDI, representante de órgão estatal (entrevistado 1); um representante da área técnica de outro órgão estatal (entrevistado 2); um ex-presidente do CNDI, de órgão estatal (entrevistado 3); e um ex-presidente do CNDI vinculado à entidade civil não-governamental (entrevistado 4).

Procedeu-se a análise de conteúdo temática dos documentos e entrevistas, considerando os eixos definidos no estudo.

\section{Resultados}

\section{Configuração político-institucional}

A partir da Constituição de 1988, observamse avanços na institucionalização de instâncias de controle social nas áreas da Seguridade Social ${ }^{12,13}$. A lei que instituiu a Política Nacional do Idoso (PNI), em 1994, previu a criação do CNDI, com o objetivo de "viabilizar o convívio, a integração e a ocupação do idoso na sociedade, mediante sua inclusão no processo de formulação de políticas públicas destinadas a seu grupo social"14. No entanto, a criação do Conselho foi adiada, ocorrendo somente oito anos depois, ligado ao Ministério da Justiça ${ }^{15,16}$.

Em 2004, o CNDI foi regulamentado como um órgão colegiado de caráter deliberativo sob encargo do Ministério da Previdência e Assistência Social ${ }^{16}$. Já em 2009, passou a integrar a estrutura da Secretaria Especial dos Direitos $\mathrm{Hu}$ manos (SEDH) da Presidência da República, vinculada ao Ministério da Justiça.

De forma geral, o CNDI tem como objetivo acompanhar a aplicação do Estatuto do Idoso, da PNI e dos demais atos normativos relacionados ao atendimento do idoso. Entre suas competências destaque-se: a) estimular a ampliação dos mecanismos de participação e controle social; b) apoiar os Conselhos Estaduais, do Distrito Federal e Municipais dos Direitos do Idoso, os órgãos estaduais, municipais e entidades não-governamentais; c) acompanhar a elaboração e a execução da proposta orçamentária da União; d) promover a cooperação entre os governos da União, dos Estados, do Distrito Federal e dos Municípios e a sociedade civil organizada na formulação e execução da política nacional de atendimento dos direitos do idoso; entre outras.

O CNDI tem caráter paritário, sendo composto por 14 membros do Poder Executivo e 14 da sociedade civil. Além da Secretaria Especial dos Direitos Humanos da Presidência da República (SEDH), integram o Conselho os seguintes ministérios: Justiça; Relações Exteriores; Trabalho e Emprego; Educação; Saúde; Cultura; Esporte; Turismo; Cidades; Ciência e Tecnologia; Desenvolvimento Social e Combate à Fome; Previdência Social; Planejamento, Orçamento e Gestão.

Já os membros da sociedade civil devem pertencer a entidades civis organizadas, com atuação na promoção e defesa dos direitos da pessoa idosa. De acordo com o Regimento do CNDI, considera-se organização da sociedade civil a entidade de direito privado sem fins lucrativos, de interesse e/ou de utilidade pública que tenha atuação no âmbito nacional, com representação em no mínimo cinco unidades da federação e três regiões.

Os critérios de elegibilidade para os membros das entidades não governamentais são descritos no Quadro 1.

O Conselho é composto por: Plenário, Comissões Permanentes e Temporárias e Secretaria Executiva. A Presidência do CNDI tem funções específicas, ficando a coordenação dos trabalhos das Comissões a cargo da Vice-presidência ${ }^{6}$.

As comissões permanentes são: Políticas Públicas; Orçamento e Finanças; Normas; Articulação com os Conselhos e Comunicação Social. A partir de 2010 também foi criada a Comissão de Gestão do Fundo Nacional do Idoso. O Quadro 2 abaixo apresenta as principais atribuições das comissões.

A escolha dos membros da sociedade civil é realizada por processo eleitoral, a cada dois anos. Já a presidência e a vice-presidência são alternadas a cada biênio entre os segmentos da sociedade civil e do governo. O Quadro 3 mostra as organizações que ocuparam a presidência do Conselho entre 2002 e 2016.

Entre as entidades da sociedade civil, se destacaram na presidência aquelas com trajetória expressiva na luta pelos direitos dos idosos. Em relação aos órgãos governamentais, ao longo das gestões, o Ministério da Saúde ocupou a presidência apenas uma vez. Nas demais gestões sob comando de órgãos governamentais, a presidência foi assumida por membros da SEDH.

As reuniões do CNDI têm periodicidade bimestral. A Figura 1 mostra a frequência de participação dos representantes dos órgãos governamentais e entidades não governamentais nas reuniões no período.

Quanto às entidades civis não governamentais, a Confederação Brasileira de Aposentados e Pensionistas - COBAP, a Associação Nacional de 
Quadro 1. Critérios para a admissão de membros de entidades civis não governamentais.

\begin{tabular}{|l|l|}
\hline \multicolumn{1}{|c|}{ Definição } & \multicolumn{1}{c|}{ Caráter das organizações elegíveis } \\
\hline $\begin{array}{l}\text { Um representante e respectivo suplente de cada um dos } \\
\text { seguintes segmentos da sociedade civil atuantes no campo } \\
\text { da defesa ou da promoção dos direitos da pessoa idosa }\end{array}$ & $\begin{array}{l}\text { a) Organizações de trabalhadores urbanos } \\
\text { e rurais; b) Organizações de Empregadores } \\
\text { urbanos e rurais; c) Orgãos Fiscalizadores do } \\
\text { Exercício Profissional; d) Organizações de } \\
\text { Educação, ou Lazer, ou Cultura, ou Esporte, ou } \\
\text { Turismo. }\end{array}$ \\
\hline $\begin{array}{l}\text { Dois representantes e respectivos suplentes de cada um dos } \\
\text { seguintes segmentos da sociedade civil atuantes no campo } \\
\text { da defesa ou da promoção dos direitos da pessoa idosa }\end{array}$ & $\begin{array}{l}\text { a) Organizações da Comunidade Cientifica; } \\
\text { b) Organizações de Aposentados e Pensionistas. }\end{array}$ \\
\hline $\begin{array}{l}\text { Três representantes e respectivos suplentes de cada um dos } \\
\text { seguintes segmentos da sociedade civil atuantes no campo } \\
\text { da defesa ou da promoção dos direitos da pessoa idosa }\end{array}$ & $\begin{array}{l}\text { a) Organizações de Defesa de Direitos; } \\
\text { b) Organizações de Atendimento à Pessoa Idosa. }\end{array}$ \\
\hline
\end{tabular}

Fonte: Elaboração própria a partir do regimento interno do CNDI.

Quadro 2. Principais atribuições das comissões permanentes do CNDI.

\begin{tabular}{|c|c|}
\hline $\begin{array}{c}\text { Comissões } \\
\text { Permanentes }\end{array}$ & Principais atribuições \\
\hline $\begin{array}{l}\text { Comissão } \\
\text { de Políticas } \\
\text { Públicas }\end{array}$ & $\begin{array}{l}\text { I- Acompanhar e avaliar a Política Nacional do Idoso; II- assessorar, acompanhar e avaliar } \\
\text { o plano estratégico nacional de implementação das deliberações da Conferência Nacional } \\
\text { dos Direitos da Pessoa Idosa; III- criar mecanismos e estratégias para assessorar e monitorar } \\
\text { a formulação e operacionalização dos planos estratégicos Estaduais, Distrital e Municipais, } \\
\text { decorrentes das respectivas conferências; entre outras. }\end{array}$ \\
\hline $\begin{array}{l}\text { Comissão de } \\
\text { Orçamento e } \\
\text { Finanças }\end{array}$ & $\begin{array}{l}\text { I- Apreciar e acompanhar as diretrizes, propostas e execução orçamentárias pertinentes ao } \\
\text { segmento idoso elaboradas pelos Ministérios; II- Assessorar na formulação da proposta } \\
\text { orçamentária dos Planos Estratégicos das unidades federativas e a execução financeira; III - } \\
\text { identificar as necessidades da Presidência e das demais Comissões no que diz respeito à gestão } \\
\text { administrativa e financeira do CNDI; IV- solicitar que a Secretaria de Direitos Humanos } \\
\text { informe os recursos previstos para a gestão e funcionamento do CNDI, entre outras. }\end{array}$ \\
\hline $\begin{array}{l}\text { Comissão de } \\
\text { Normas }\end{array}$ & $\begin{array}{l}\text { I- Acompanhar, analisar, propor sobre a constitucionalidade das matérias que lhe forem } \\
\text { submetidas; II- propor alteração no regimento interno do CNDI; III- propor a realização de } \\
\text { estudos, debates e pesquisas sobre a aplicação e os resultados estratégicos alcançados pelos } \\
\text { programas e projetos de atendimento ao idoso. }\end{array}$ \\
\hline $\begin{array}{l}\text { Comissão de } \\
\text { Articulação } \\
\text { com Conselhos } \\
\text { e Comunicação } \\
\text { Social }\end{array}$ & $\begin{array}{l}\text { I- organizar coletânea de instrumentos legais que versem sobre a PNI; II - organizar } \\
\text { Resoluções do CNDI, resgatando a memória histórica; III - divulgar as atividades do CNDI e } \\
\text { da PNI; IV - colaborar na divulgação das ações realizadas pelas entidades civis representativas } \\
\text { da pessoa idosa em âmbito nacional; V - recomendar às Comissões Permanentes que seja } \\
\text { dada ênfase especial ao trabalho integrado governo e sociedade, etc. }\end{array}$ \\
\hline $\begin{array}{l}\text { Comissão } \\
\text { de Gestão } \\
\text { do Fundo } \\
\text { Nacional do } \\
\text { Idoso }\end{array}$ & $\begin{array}{l}\text { I- Elaborar anualmente os planos de trabalho e de aplicação dos recursos do Fundo; II - } \\
\text { definir os procedimentos e critérios a serem contemplados nos Editais para a aprovação de } \\
\text { projetos a serem financiados com recursos do Fundo ; III - demandar aos responsáveis as } \\
\text { informações necessárias ao acompanhamento e avaliação das atividades apoiadas pelo Fundo; } \\
\text { IV - desenvolver atividades relacionadas à ampliação da captação de recursos para o Fundo; } \\
\text { V- avaliar e aprovar os pedidos de registro das instituições e inscrição dos programas junto ao } \\
\text { CNDI, entre outras. }\end{array}$ \\
\hline
\end{tabular}

Fonte: Elaboração própria feita a partir do Regimento Interno do CNDI.

Gerontologia - ANG e a Pastoral da Pessoa Idosa foram as que mais estiverem presentes ao longo dos doze anos. As duas primeiras organizações têm sido protagonistas do movimento pró direitos dos idosos no Brasil ${ }^{17,18}$.
A ANG, fundada em 1985, tem por finalidade contribuir para a melhoria das condições de vida da população idosa por meio da defesa de políticas para esse grupo, promoção de espaços de trocas entre especialistas e produção de conheci- 
Quadro 3. Quadro resumo dos órgãos governamentais e entidades da sociedade civil que ocuparam a presidência do CNDI - 2002 a 2016.

\begin{tabular}{|c|l|}
\hline Gestão & \multicolumn{1}{c|}{ Entidades que ocuparam a presidência } \\
\hline $2002-2004$ & Associação Nacional de Gerontologia - ANG \\
\hline $2004-2005$ & Subsecretaria de Promoção e Defesa dos Direitos \\
\hline $2006-2008$ & $\begin{array}{l}\text { Associação Nacional dos Membros do Ministério Público de Defesa dos Direitos dos Idosos e } \\
\text { Pessoas com Deficiência-AMPID }\end{array}$ \\
\hline $2008-2010$ & Ministério da Saúde \\
\hline $2010-2012$ & Sociedade Brasileira de Geriatria e Gerontologia - SBGG \\
\hline $2012-2014$ & Secretaria Especial de Direitos Humanos da Presidência da República (SDH) \\
\hline $2014-2016$ & Confederação Brasileira de Aposentados e Pensionistas-COBAP \\
\hline
\end{tabular}

Fonte: Elaboração própria a partir das atas de reunião do CNDI.

mento sobre o envelhecimento. Essa Associação fomentou uma mobilização nacional no final da década de 90 que culminou na elaboração do documento "Políticas para a $3^{\text {a }}$ idade nos anos 90", inspiração para o texto da PNI e criação do CNDI.

A COBAP, criada em 1985, ganhou visibilidade durante a Assembleia Nacional Constituinte ao reivindicar a melhoria dos benefícios previdenciários e propiciar maior visibilidade às demandas dos idosos.

O tempo de atuação e a organicidade de trajetória dessas organizações ajudam a compreender a sua assiduidade ao longo das reuniões do CNDI, bem como seu papel decisivo na implementação da $\mathrm{PNI}^{17}$.

A Pastoral da Pessoa Idosa, vinculada à Conferência Nacional dos Bispos do Brasil, foi a segunda mais assídua nas reuniões do CNDI. Criada em 2004, a Pastoral tem como objetivo melhorar a qualidade de vida dos longevos mediante ações junto às redes comunitárias e sociofamiliares ${ }^{19}$.

Destaque-se também a presença frequente de organizações de defesa de direitos como a Associação Nacional dos Defensores Públicos, a Associação Nacional de Membros do Ministério Público de Defesa dos Direitos dos Idosos e Pessoas com Deficiência e a Ordem dos Advogados do Brasil (OAB). A assiduidade dessas entidades é fundamental para monitorar as políticas a partir dos preceitos legais.

As entidades civis têm sido decisivas na defesa da temática do idoso na agenda de prioridades do Estado. A Sociedade Brasileira de Geriatria e Gerontologia (SBGG) também teve papel relevante e pioneiro na luta pela ampliação dos direitos dos idosos, assim como o SESC e a OAB.

Em relação ao governo, além da Secretaria Especial de Direitos Humanos - SEDH, os minis- térios que mais participaram foram os de: Saúde; Desenvolvimento Social e Combate à Fome (MDS); Previdência Social (MPS) e Educação (MEC). A assiduidade desses órgãos expressou os eixos prioritários da PNI e do Estatuto do Idoso.

Desde 2009, a Secretaria do CNDI é vinculada à SEDH, que é responsável por grande parte das iniciativas e políticas específicas para a pessoa idosa. Isso explica a sua frequente participação nas reuniões do Conselho.

O Ministério da Saúde é um dos órgãos fundamentais no desenvolvimento de políticas para o bem-estar da população idosa. A PNI destaca como competências da área da saúde: garantia de assistência integral à saúde; prevenção, promoção e recuperação da saúde; aplicação de normas para funcionamento de instituições geriátricas, com fiscalização pelos gestores do Sistema Único de Saúde; criação de serviços alternativos de saúde para o idoso; entre outros. No Estatuto do Idoso, o capítulo IV também se dedica ao direito à saúde.

O Ministério do Desenvolvimento Social e Combate à Fome (MDS) é responsável por políticas essenciais na promoção do bem-estar dos idosos, como as de Assistência Social. Em seu âmbito, se inserem ações de proteção social básica e especial que priorizam os idosos. O Benefício de Prestação Continuada (BPC), um mecanismo fundamental de garantia de renda básica à pessoa idosa, integra a proteção social básica, no âmbito do Sistema Único de Assistência Social - SUAS.

A PNI ressalta a importância da área da Assistência que deve: prestar serviços e desenvolver ações para o atendimento das necessidades básicas do idoso, mediante a participação das famílias, da sociedade e de entidades governamentais e não-governamentais; estimular alternativas de atendimento ao idoso; promover a capacitação de recursos para atendimento ao idoso; entre ou- 


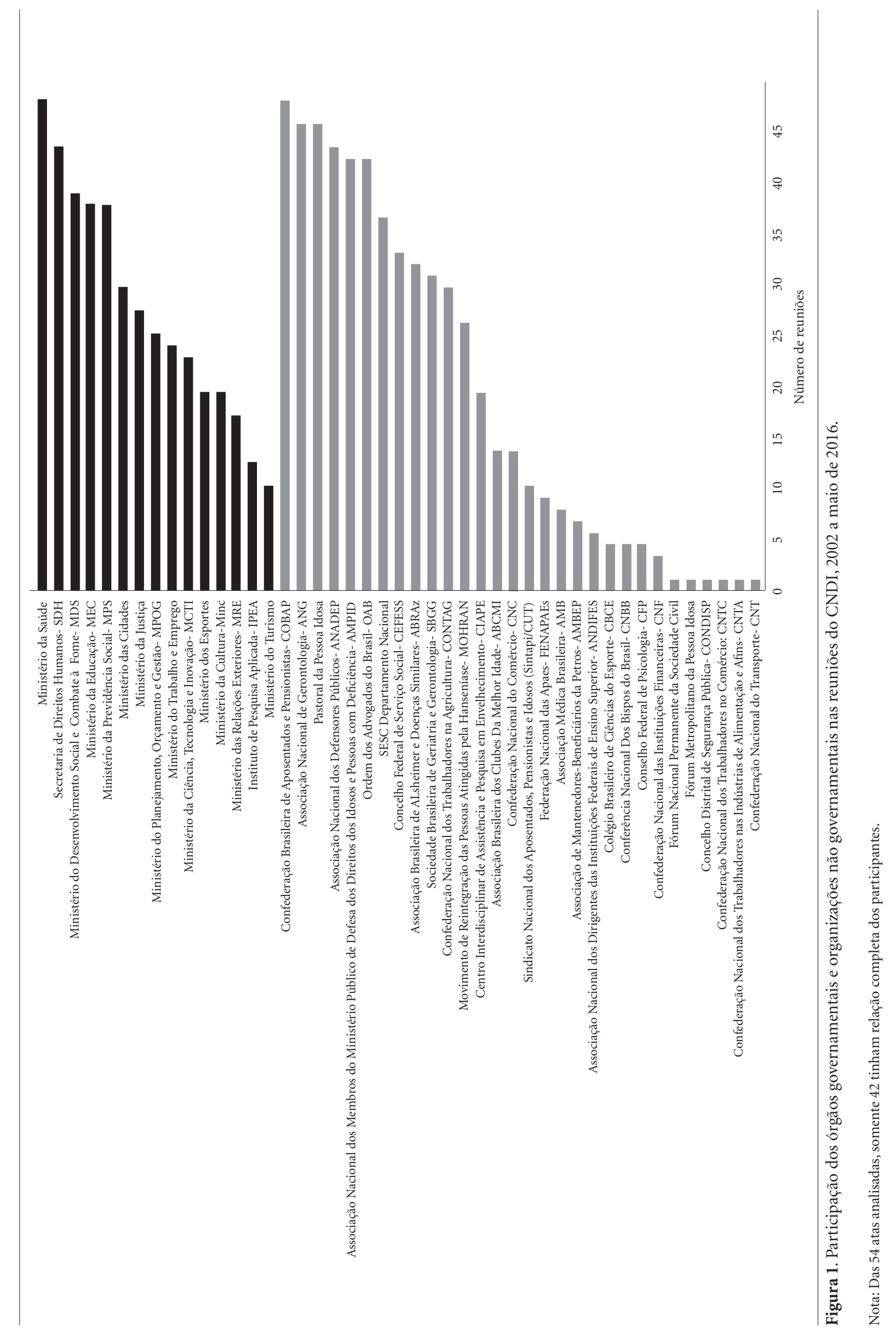


tros. O Estatuto do Idoso também compreende um capítulo sobre as atribuições da área na assistência aos idosos.

Outro Ministério assíduo das reuniões do CNDI é o da Previdência Social (MPS), cuja finalidade é diretamente atrelada à proteção aos idosos. O benefício contributivo da previdência se configura como a principal fonte de renda para esse grupo. A solicitação do BPC também se dá nas agências do Instituto Nacional de Seguro Social (INSS), vinculado ao MPS, embora a coordenação do benefício seja feita pelo MDS. A política da previdência, por meio das aposentadorias e pensões, favorece no espaço familiar uma revalorização das pessoas idosas que "obtêm uma espécie de salvaguarda de subsistência familiar, invertendo o papel social de assistidos para assistentes, no contexto da estratégia de sobrevivência das famílias pobres"20.

A PNI tratou da previdência no que concerne à priorização do atendimento do idoso nos requerimentos dos benefícios previdenciários. Também salienta a necessidade de estímulo a programas de preparação para a aposentadoria nos setores público e privado com antecedência mínima de dois anos ao afastamento. O Estatuto do Idoso dedicou o Capítulo VII à área.

A participação do MEC pode ser compreendida a partir das orientações preconizadas na PNI, reforçadas pelo Estatuto do Idoso, como: a necessidade de adequar material didático a programas educacionais destinados ao idoso; inserir nos currículos mínimos conteúdos voltados para o processo de envelhecimento; incluir a Gerontologia e a Geriatria como disciplinas curriculares nos cursos superiores; e desenvolver programas educativos nos meios de comunicação, a fim de informar a população sobre o processo de envelhecimento $^{21}$.

O Ministério das Cidades participa do CNDI, seguindo as orientações da PNI e do Estatuto do Idoso quanto ao direito do idoso a habitações compatíveis com suas necessidades. O Programa Minha Casa, Minha Vida, criado em 2009, que visa incentivar a aquisição de novas unidades habitacionais ou requalificação de imóveis urbanos para famílias com baixa renda, prevê a disponibilidade de unidades adaptáveis ao uso por pessoas idosas $^{22}$. O Estatuto do Idoso afirma que pelo menos 3\% das unidades devem ser reservadas para as pessoas idosas. Investimentos em acessibilidade voltados a pessoas com restrição de mobilidade nas cidades também são relevantes para os idosos.

A assiduidade de alguns ministérios nas reuniões do CNDI, portanto, expressa o esforço de construção de ações que podem afetar de forma positiva a pessoa idosa: atenção à saúde; provisão de condições materiais que possibilitem condições mínimas de bem-estar em situações de vulnerabilidade; acessibilidade e moradia adequadas; sensibilização e ampliação dos conhecimentos sobre o envelhecimento e inclusão dos idosos. No entanto, a frequência dos ministérios per se não assegura que as ações das áreas sejam integradas.

Identificaram-se dificuldades na participação de alguns órgãos governamentais nas reuniões e atividades do CNDI. Por exemplo, na criação do grupo de trabalho para elaboração de critérios de utilização do Fundo Nacional do Idoso, a composição do grupo foi feita exclusivamente por representantes não governamentais, o que demandou uma nova rodada de convites à participação dos órgãos de governo.

A insuficiente participação de membros governamentais nas reuniões ou deliberações foi destacada por uma conselheira representante da sociedade civil durante uma reunião:

A sociedade civil tem cumprido a sua obrigação, o seu papel, mas o que nós observamos desde [...] o primeiro mandato foi que o Governo não cumpriu com as suas promessas e compromissos assumidos, principalmente da participação das reuniões deste colegiado. Ainda ontem mesmo estávamos com dificuldade para composição de comissões. Então o que eu quero salientar é que ainda continuamos nessa expectativa de que o Governo venha para cá e cumpra aquilo que é prometido, que não fique na dependência só da sociedade civil porque isto é um colegiado, há uma paridade de membros e os conselheiros, principalmente os que vierem para reunião, devem permanecer pelo menos durante os períodos das reuniões. (Ata da 50a Reunião Ordinária do CNDI de 2011)

Uma das entrevistadas também apontou a presença incipiente dos órgãos governamentais, sobretudo no que se refere à deliberação das propostas do Conselho:

[...] o Conselho tem 14 representantes do governo, 14 da sociedade civil. Agora, como os demais Conselhos, representantes de governo faltam muito às reuniões de comissões, não têm aquela garra, aquele envolvimento com a questão do envelhecimento. Os 14 da sociedade civil são sempre as mesmas instituições, mudam os atores, mas não as instituições, porque são poucas as de âmbito nacional na área do idoso. Isso que precisa. O Conselho tem que fazer o seu papel de controle democrático, de acompanhar nas três esferas de governo como está sendo acompanhado, pressionado, para a im- 
plementação da política do idoso. Porque se não houver pressão, organização ou articulação, pouco vamos avançar (Entrevistada 1)

A frequência dos órgãos governamentais nas reuniões ordinárias do CNDI nem sempre se traduziu em efetividade de participação. Por outro lado, destacou-se a atuação do Ministério da Saúde nas comissões permanentes do CNDI, bem como a importância desse espaço para a sua interação com outros órgãos e entidades da sociedade civil:

Sou conselheira titular, de 2012 até 2016. Esse ano nós vamos fazer nova indicação. Também coordenava a comissão de politicas, como representante de governo. Então é muito importante a participação, a qualificação das participações do conselho, porque a gente está ali sentada na mesma mesa com a sociedade civil e com representantes de outros ministérios, que muitas vezes a gente nem tem tanta proximidade. Então, acho que ainda tem muito o que avançar, não tenho dúvida disso. A gente fez esse ano a $4^{a}$ Conferência Nacional de Direitos da Pessoa Idosa numa parceria muito boa. Isso aproxima as politicas, você pensa em estratégias que englobam outros setores. A gente trabalha muito, eu particularmente acho que o trabalho intersetorial é fundamental. A Saúde sozinha não vai resolver as questões, em especial da pessoa idosa (Entrevistado 2)

\section{Agenda política}

Os temas mais debatidos nas reuniões do CNDI estavam presentes na PNI, o que reforça o caráter desta na definição da agenda. Estes foram agregados em quatro eixos: (i) Legislação, adequação e efetivação da Política Nacional do Idoso e Estatuto do Idoso; (ii) Fortalecimento do controle social; (iii) Orçamento público federal voltado aos idosos; (iv) Redes de promoção, proteção e defesa de direitos dos idosos.

i. Legislação, adequação e efetivação da Política Nacional do Idoso e Estatuto do Idoso

O CNDI tem o papel de acompanhar, supervisionar, fiscalizar e avaliar a PNI, bem como as ações dela decorrentes em consonância com o Estatuto do Idoso. A análise das atas permitiu identificar temas da PNI frequentemente debatidos, bem como as medidas e encaminhamentos relativos a cada um, conforme resumido no Quadro 4.

Para alguns temas, houve dificuldades de encaminhar propostas. Um exemplo concerne à formação de recursos humanos nas áreas de geriatria e gerontologia. Apesar dos debates so- bre a necessidade de capacitação continuada aos trabalhadores do SUS e de outros ministérios no que se refere ao cuidado dos idosos, não houve ações concretas.

No que diz respeito à aplicação de normas de funcionamento e fiscalização de instituições geriátricas e similares no âmbito do SUS, foram feitas visitas de inspeção. Contudo, algumas ações foram realizadas pelo Conselho Federal de Psicologia junto aos Conselhos Regionais e em parceria com a $\mathrm{OAB}$, sem a participação direta de órgãos governamentais.

Quanto à criação de incentivos e alternativas de atendimento ao idoso, houve tentativas de regulamentar os serviços e programas de atenção que integrariam a Rede Nacional de Proteção e Defesa da Pessoa Idosa (RENADI). Porém, esta não foi concretizada.

No que concerne à inserção nos currículos de conteúdos voltados para o processo de envelhecimento, abordou-se o incentivo à capacitação $\mathrm{e}$ reciclagem dos recursos humanos; o estímulo à capacitação em instituições de ensino públicas e privadas e a busca pela inclusão da temática do envelhecimento nas disciplinas do ensino fundamental.

Sobre o Estatuto do Idoso, as discussões giraram em torno da readequação de alguns artigos, como os relativos ao direito à gratuidade no transporte público e a regulamentação e fiscalização das Instituições de Longa Permanência.

ii. Fortalecimento dos conselhos locais de idosos

Os conselhos locais de idosos constituem-se como lócus de elaboração e controle de políticas, podendo ser representativos do grau de maturidade do movimento social que representa a população idosa. Mesmo antes do CNDI, alguns conselhos locais já existiam, como o do Estado de São Paulo ${ }^{18}$. Contudo, ainda é expressivo o número de Estados e municípios que têm dificuldades na implementação desses conselhos.

A PNI estimulou a criação de conselhos estaduais e municipais ao delegar a essas instâncias responsabilidades na promoção dos direitos dos idosos. Quase 60\% dos conselhos locais surgiram a partir da $\mathrm{PNI}^{18}$.

Os debates no CNDI se centraram na necessidade de fortalecer os conselhos do idoso, envolvendo as seguintes iniciativas: levantamento dos conselhos Estaduais e Municipais do Idoso; sugestão da criação de um sistema de informação para cadastrar os conselhos; identificação de problemas para o planejamento; e elaboração de uma cartilha de sensibilização para criação dos conselhos. Como avanço, a partir do Fundo Na- 
Quadro 4. Temas do PNI mais debatidos nas reuniões do CNDI e encaminhamentos.

\begin{tabular}{|c|c|}
\hline Temas da PNI debatidos & Encaminhamentos \\
\hline $\begin{array}{l}\text { a) Capacitação e reciclagem dos recursos humanos } \\
\text { nas áreas de geriatria e gerontologia e na prestação de } \\
\text { serviços; }\end{array}$ & Não houve encaminhamentos concretos. \\
\hline $\begin{array}{l}\text { b) Implementação de sistema de informações que } \\
\text { permita a divulgação da política em cada nível de } \\
\text { governo; }\end{array}$ & $\begin{array}{l}\text { A tentativa de publicização de ações referentes a políticas } \\
\text { e ações ficaram a cargo do GT de comunicação. }\end{array}$ \\
\hline $\begin{array}{l}\text { c) promover as articulações intraministeriais e } \\
\text { interministeriais necessárias à PNI; }\end{array}$ & $\begin{array}{l}\text { As tentativas de articulação ficaram restritas a iniciativas } \\
\text { conjuntas do Ministério da Saúde e MDS }\end{array}$ \\
\hline $\begin{array}{l}\text { d) estimular a criação de incentivos e de alternativas } \\
\text { de atendimento ao idoso, como centros de convivência, } \\
\text { casas-lares, atendimentos domiciliares e outros; }\end{array}$ & $\begin{array}{l}\text { Realização de um levantamento censitário em todas as } \\
\text { Instituições de Longa Permanência cadastradas e que } \\
\text { fizeram parte do censo SUAS. }\end{array}$ \\
\hline $\begin{array}{l}\text { e) adotar e aplicar normas de funcionamento às } \\
\text { instituições geriátricas e similares, com fiscalização pelos } \\
\text { gestores do Sistema Único de Saúde (SUS); }\end{array}$ & $\begin{array}{l}\text { As inspeções ocorreram, mas não por parte dos gestores } \\
\text { do SUS. }\end{array}$ \\
\hline $\begin{array}{l}\text { f) inserir nos currículos mínimos, nos diversos níveis do } \\
\text { ensino formal, conteúdos voltados para o processo de } \\
\text { envelhecimento }\end{array}$ & Não houve encaminhamentos concretos. \\
\hline g) diminuir barreiras arquitetônicas e urbanas e; & $\begin{array}{l}\text { Esforço em diminuir barreiras para os idosos através de } \\
\text { melhorias no espaço público a partir de ações e reuniões } \\
\text { com o Ministério das Cidades }\end{array}$ \\
\hline $\begin{array}{l}\text { h) zelar pela aplicação das normas sobre o idoso } \\
\text { determinando ações para evitar abusos e lesões a seus } \\
\text { direitos. }\end{array}$ & $\begin{array}{l}\text { O plano e o manual de enfrentamento à violência } \\
\text { contra a pessoa idosa foram instrumentos que buscaram } \\
\text { conscientizar e informar sobre os abusos sofridos pelos } \\
\text { idosos e como enfrenta-los; Inclusão das denúncias } \\
\text { referentes à violência aos idosos no disque } 100 \text { Direitos } \\
\text { Humanos e posterior capacitação dos atendentes. }\end{array}$ \\
\hline
\end{tabular}

Fonte: Elaboração própria.

cional do Idoso, o CNDI apoiou a estruturação e equipagem dos conselhos que apresentavam estruturas físicas precárias.

iii. Orçamento Público Federal voltado aos idosos

O CNDI tem como atribuição "acompanhar a elaboração e a execução da proposta orçamentária da União, indicando modificações necessárias à consecução da política formulada para a promoção dos direitos do idoso" ${ }^{16}$, o que sugere a necessidade de previsão orçamentária para ações voltadas à população idosa.

Em algumas reuniões do CNDI deliberou-se que fossem levantadas as ações dos ministérios direcionadas para os idosos. Porém, a Secretaria de Orçamento Federal informou ao Conselho a inexistência de ação orçamentária específica destinada aos idosos. As ações para esse grupo estão incorporadas dentro de programas gerais nos orçamentos setoriais, o que dificulta seu monitoramento.

Um projeto de criação de um fundo para a população idosa, apresentado em 2005, permaneceu durante anos na Comissão de Finanças e
Tributação. Nas reuniões do CNDI enfatizou-se a necessidade de acelerar o processo junto ao Congresso, diante da compreensão de que um fundo orçamentário exclusivo favoreceria o avanço das ações preconizadas no Estatuto do Idoso.

Em 2010 foi instituído o Fundo Nacional do Idoso (FNI) e autorizada a criação de fundos congêneres nas esferas estaduais e municipais ${ }^{23}$. O FNI resultou de sucessivas discussões no âmbito do CNDI diante da "inexistência de incentivos fiscais, como a dedução de impostos, para doações em dinheiro feitas às instituições prestadoras de serviços voltados à população idosa"24. O objetivo é financiar programas e ações a fim de assegurar os direitos dos idosos e criar condições para promover sua autonomia, integração e participação efetiva na sociedade. No entanto, sua finalidade é complementar, sendo vedada sua utilização para o financiamento de políticas de caráter continuado ${ }^{23,25}$.

O FNI tem como receitas: recursos públicos consignados no Orçamento da União, dos estados, dos municípios e do Distrito Federal; 
contribuições de governos e organismos internacionais; e doações de pessoas físicas e jurídicas, dedutíveis do Imposto de Renda.

A administração do Fundo é do Poder Executivo, sendo "competência do Conselho Nacional dos Direitos da Pessoa Idosa gerir o Fundo Nacional do Idoso e fixar os critérios para sua utilização"23:

O CNDI fiscaliza, acompanha, propõe, delibera onde vai ser usado, mas não movimenta. O Fundo é um complemento, as politicas do idoso estão nos municípios, nos estados, através do SUS, da Previdência Social, da Assistência Social, do CRAS, CREAS, dos Centros de Convivência. (Entrevistado 3)

A instituição do Fundo significou um ganho dos movimentos sociais, que colocaram na agenda do Estado a urgência de gerar recursos financeiros para viabilizar ações para o bem-estar os idosos. A escolha de alocação e investimento dos recursos em determinados benefícios e programas pode ajudar a compreender as prioridades estatais nesse âmbito.

Contudo, diante da introdução de novos processos administrativos relacionados à gerência do FNI, houve dificuldades iniciais quanto às diretrizes e normas para utilização do fundo. Por isso, constituiu-se um grupo de trabalho para subsidiar o Conselho no desenvolvimento de estratégias para captação e utilização de recursos.

A partir de 2013, os debates nas reuniões sugerem o funcionamento do Fundo, incluindo formas de angariar doações e o estabelecimento de editais visando a seleção de entidades que tivessem projetos compatíveis com os critérios de utilização regulamentados por resolução da SEDH de $2012^{26}$.

iii. Redes de promoção, proteção e defesa de direitos dos idosos

Identificou-se a busca de construção de ações abrangentes para os idosos a partir de redes intersetoriais de defesa e promoção de direitos, conforme previu a PNI. Buscou-se estabelecer a RENADI, caracterizada como um pacto entre os gestores de políticas públicas com o objetivo de promover a intersetorialidade na proteção aos idosos, visando evitar situações de vulnerabilidade social desse grupo.

Para operacionalização da RENADI, propôsse o Plano Técnico de Articulação de Rede de Promoção dos Direitos da Pessoa Idosa- PLANTAR, que teria como objetivo integrar políticas para a construção de uma agenda comum de trabalho entre governos, sociedade civil e organismos internacionais. Contudo, apesar de a proposta do RENADI ter sido tema da $1^{\text {a }}$ Conferên- cia Nacional do Idoso em 2006, a Rede ainda não havia se concretizado até 2011 e a maior parte das iniciativas permanecia em discussão.

Em suma, a agenda do Conselho no período foi influenciada por: (i) diretrizes da PNI e do Estatuto do Idoso; (ii) normas que norteiam o funcionamento do CNDI; e (iii) demandas trazidas pelas representações da sociedade civil e pelos conselhos estaduais e municipais do idoso. Esses três elementos repercutiram na priorização dos temas e condução das ações.

\section{Considerações finais}

O Brasil apresentou avanços institucionais nas últimas décadas nas políticas para os idosos, tanto do ponto de vista constitucional, ao propor uma Seguridade Social abrangente, quanto por meio de estratégias especificas, como o Estatuto do Idoso. O CNDI representa uma estrutura inovadora de governança, que procura promover a articulação intersetorial entre órgãos públicos e ampliar a participação da sociedade civil nas políticas para os idosos.

Debert e Oliveira ${ }^{27}$ atestam a importância de conselhos participativos, que favorecem a influência e controle da sociedade civil institucionalizada sobre o Estado na elaboração e implementação de políticas públicas. Cabe destacar a estrutura horizontal que caracteriza a tomada de decisões, com presença de agentes estatais de diferentes órgãos; a existência de comissões para viabilizar as ações; a densidade organizacional da sociedade civil; e a tentativa de articulação entre agendas do Estado e da sociedade civil.

Programas sociais voltados para a população idosa vêm sendo expandidos em diversos países, sobretudo os desenvolvidos, influenciados pelo modelo de proteção social em cada contexto ${ }^{28}$. Contudo, não foi possível identificar na literatura internacional o funcionamento de espaços institucionais baseados na articulação intersetorial e na participação do Estado e sociedade civil voltados para esse grupo em moldes similares ao CNDI, o que sugere o caráter inovador dessa instância.

No que se refere à agenda política, destaque-se o papel do CNDI na defesa da implementação da legislação de proteção dos idosos a partir de estratégias junto as diferentes esferas e Poderes (Executivo, Judiciário e Legislativo). Como exemplos, houve a tentativa de construção da RENADI, o desenvolvimento do Plano e Manual de Enfrentamento à Violência contra a Pessoa Idosa, a criação do Fundo Nacional do Idoso e o fortalecimento 
dos conselhos locais dos idosos. A institucionalização de um espaço que conjugou participação da sociedade civil e governo propiciou mecanismos para que demandas fossem debatidas, encaminhadas e eventualmente atendidas.

O CNDI se caracteriza pela diversidade de temas tratados, na tentativa de abarcar as necessidades da população idosa. As diretrizes e orientações da PNI e do Estatuto têm norteado os debates, mas nem todos os dispositivos legais têm sido cumpridos. A pesquisa mostrou limites na capacidade de atuação do Conselho de encaminhar deliberações para que as propostas se traduzissem em ações concretas. Algumas dificuldades foram: escassez e dispersão dos recursos que financiam as políticas para os idosos por diferentes órgãos; entraves na relação entre entidades da sociedade civil e governo; e insuficiente envolvimento de alguns órgãos governamentais na proposição e avaliação das ações para os idosos. Por outro lado, o Ministério da Saúde foi um dos órgãos com participação mais intensa.

A análise da participação e articulação entre atores na formulação e acompanhamento das políticas no CNDI foi importante para a compreensão dos avanços e limites da capacidade de atuação dessa instância para a concretização das ações para os idosos. Observou-se que, apesar da interação entre o Estado e sociedade civil na proposição de diretrizes e ações para os idosos, há constrangimentos institucionais e políticos que prejudicam a efetividade dessa instância no encaminhamento das propostas. A análise das atas sugere que o poder instituinte da política não se encerra na fase da institucionalização, sendo preciso manter condições de cidadania ativa (práxis como pressão política permanente). O Conselho seria uma arena vocacionada para esse propósito. Todavia, muitos são os desafios para que esse espaço se consolide como instância de operacionalização e garantia de efetividade das políticas.

A intersetorialidade é fundamental para o avanço das políticas para os idosos. Durante as reuniões, enfatizou-se a necessidade de construção de ações em várias dimensões da vida social: as relacionadas às Instituições de Longa Permanência e redes de serviço socioassistenciais; habitação; mobilidade; ensino para os idosos, entre outras. O CNDI se notabilizou pela tentativa de articulação entre as diferentes áreas relevantes para a construção de uma rede integrada de proteção aos idosos. Porém, o fortalecimento da capacidade de atuação do Conselho esbarra em dificuldades de articulação entre setores e na não priorização da temática do envelhecimento por alguns órgãos governamentais, que dificultam a efetivação dos direitos legais.

A partir da Constituição de 1988, os mecanismos de participação social ampliaram a possibilidade de influência de atores não governamentais sobre a ação do Estado. O CNDI, ao propiciar a participação de entidades da sociedade civil e a interação entre órgãos de governo, tem sido fundamental para a densidade, a institucionalidade e a relativa estabilidade da política para os idosos. A atuação do Conselho favorece o fortalecimento de redes de atores sociais envolvidos com o tema e avanços graduais no que concerne aos direitos dos idosos.

Porém, diante das aceleradas mudanças demográficas e da situação de vulnerabilidade da maior parte da população idosa no país, essa estratégia de governança per se não tem sido suficiente para assegurar a efetivação de todos os direitos previstos no marco constitucional-legal. Persistem muitos desafios para a ampliação da proteção social aos idosos no Brasil, que requerem políticas públicas orientadas para o enfrentamento das desigualdades e a expansão dos mecanismos de solidariedade entre gerações e grupos sociais.

\section{Colaboradores}

MS Souza foi responsável pela concepção do artigo, processamento e análise de dados, redação e revisão do texto, enquanto CV Machado participou da concepção do artigo, redação e revisão final do texto.

\section{Agradecimentos}

MS Souza foi bolsista da Coordenação de Aperfeiçoamento de Pessoal de Nível Superior -Capes durante o Doutorado (Código de Financiamento 001). O trabalho de campo contou com apoio dos recursos do Proex-Capes do Programa de Pós-Graduação em Saúde Pública da Ensp/Fiocruz. CVM é bolsista de produtividade em pesquisa do Conselho Nacional de Desenvolvimento Científico e Tecnológico-CNPq. 


\section{Referências}

1. Instituto Brasileiro de Geografia e Estatística (IBGE). Sintese de Indicadores Sociais: uma análise das condições de vida da população brasileira. Rio de Janeiro: IBGE; 2015.

2. Veras R. Envelhecimento populacional contemporâneo: demandas, desafios e inovações. Rev Saude Publica 2009; 43(3):548-554.

3. Kalache A. Envelhecimento populacional no Brasil: uma realidade nova. Cad Saude Publica SciELO Public Health 1987; 3(3):217-220.

4. Souza MS. Envelhecimento, políticas públicas e exclusão social: trajetória de idosos de comunidades do Complexo de Manguinhos. Rio de Janeiro: Fiocruz; 2013.

5. Camarano AA, Pasinato MT. O Envelhecimento populacional na agenda das políticas públicas. In: Camarano AA, organizadora. Os Novos Idosos Brasileiros: muito além dos 60. Rio de Janeiro: IPEA; 2004. p. 261-300.

6. Giacomin KC. Relatório do Conselho Nacional do Idoso Gestão 2010-2012. Rev Portal Divulg 2013; (30).

7. Marques E. Os mecanismos relacionais. Rev. bras. Ci. Soc. 2007; 22(64):157-161.

8. Gonçalves A. O Conceito de Governança. In: Anais do XIV Congresso Conpedi; 2012. Manaus.

9. Lopez F. Accountability e controle social na administração pública federal. In: Instituto de Pesquisa Econômica Aplicada (IPEA), organizador. Estado, Instituições e democracia: democracia. Brasília: Ipea; 2010. Livro 9, vol. 2.

10. Marques E. Government, Political Actors and Governance in Urban Policies in Brazil and São Paulo: Concepts for a Future Research Agenda. Brazilian Polit Sci Rev 2013; 7(3):8-35.

11. Pires RRC. Intersetorialidade, arranjos institucionais e instrumentos da ação pública. Brasília: Ministério do Desenvolvimento Social e Combate à Fome; 2016. (Cadernos de Estudos Desenvolvimento Social em Debate, n. 26).

12. Carvalho JM. Os Bestializados: O Rio de Janeiro e Republica que não foi. São Paulo: Ed. Companhia das Letras; 1987.

13. Rocha E. A Constituição Cidadã e a institucionalização dos espaços de participação social: avanços e desafios. Brasília: IPEA; 1988.

14. Instituto de Pesquisa Econômica Aplicada (IPEA). $O$ Conselho Nacional dos Direitos do Idoso na Visão de seus Conselheiros. Brasília: IPEA; 2012.

15. Brasil. Decreto ${ }^{\circ} 4.227$, de 13 de maio de 2002. Cria o Conselho Nacional dos Direitos do Idoso - CNDI, e dá outras providências. Diário Oficial da União 2002; 14 maio.

16. Brasil. Resolução $\mathrm{n}^{\circ} 18$, de 11 de junho de 2012. Dispõe sobre aprovação do Regimento Interno do Conselho Nacional dos Direitos do Idoso - CNDI, consoante disposto no art. $2^{\circ}$, VIII do Decreto ${ }^{\circ} 5.109$, de 17 de junho de 2004. Diário Oficial da União 2012; 12 jun.

17. Peres MAC. Velhice, Política e Autonomia: O movimento social do idoso e as políticas da terceira idade no Brasil. Rev HISTEDBR On-line 2007; 26:144-159.
18. Borges APA. Representação da população idosa na luta por seus direitos no Brasil: o caso dos conselhos estaduais do idoso [tese]. Brasília: Universidade Católica de Brasília; 2009.

19. Cesar J, Oliveira-Filho J, Bess G, Cegielka R, Machado J, Gonçalves T, Neumann NA. Perfil dos idosos residentes em dois municípios pobres das regiões do Norte e Nordeste do Brasil: resultados de estudo transversal de base populacional. Cad Saude Publica 2008; 24(8):18351845.

20. Camarano AA, Fernandes D. A Previdência Social brasileira. In: Alcântara AO, Camarano AA, Giacomin KC, organizadores. Politica Nacional do Idoso: velhas e novas questões. Rio de Janeiro: IPEA; 2016. p. 265-294.

21. Brasil. Lei ${ }^{\circ} 8.842$, de 4 de janeiro de1994. Dispõe sobre a política nacional do idoso, cria o Conselho Nacional do Idoso e dá outras providências. Diário Oficial da União 1994; 5 jan.

22. Brasil. Ministério dos Direitos Humanos (MDH). Mapa das Políticas, Programas e Projetos do Governo Federal para a população idosa - Compromisso Nacional para o Envelhecimento Ativo. Brasília: MDH; 2015.

23. Brasil. Lei ${ }^{\circ} 12.213$, de 20 de janeiro de 2010. Institui o Fundo Nacional do Idoso e autoriza deduzir do imposto de renda devido pelas pessoas físicas e jurídicas as doações efetuadas aos Fundos Municipais, Estaduais e Nacional do Idoso; e altera a Lei no 9.250 , de 26 de dezembro de 1995. Diário Oficial da União 2010; 21 jan.

24. Rozendo A, Justo JS. "Fundo Nacional do Idoso" e as Políticas de Gestão do Envelhecimento da População Brasileira. Rev Psicol Política 2012; 12(24):283-296.

25. Alcântara ADO, Giacomin KC. Fundo Nacional do Idoso : um instrumento de fortalecimento dos Conselhos e de garantia de direitos da pessoa idosa. Rev Kairós Gerontol 2013; 16(1):143-166.

26. Brasil. Resolução $n^{\circ} 19$, de 27 de junho de 2012. Estabelece critérios para a utilização dos recursos do Fundo Nacional do Idoso e para o seu funcionamento. Diário Oficial da União 2002; 28 jun.

27. Debert GG, Oliveira GSD. Os dilemas da democracia nos conselhos de idosos. Politica Nac do Idoso velhas e novas questões. Rio Janeiro: IPEA; 2016.

28. Lynch J. Age in the Welfare State: The Origins of Social Spending on Pensioners, Workers and Children. Cambridge: Cambridge University Press; 2006.

Artigo apresentado em 15/01/2018

Aprovado em 06/03/2018

Versão final apresentada em 25/05/2018 